\title{
Atributos químicos do solo e produtividade de girassol e milho em função da aplicação de composto de lixo urbano ${ }^{1}$
}

\author{
Tiago Vinicios Strojaki ${ }^{2}$, Vanderlei Rodrigues da Silva ${ }^{2}$, \\ André Somavilla ${ }^{2}$, Clovis Orlando Da Ros ${ }^{2}$, Moacir Tuzzin de Moraes ${ }^{3}$
}

\begin{abstract}
Soil chemical attributes and sunflower and maize yield according to the application of urban waste compost

The use of composted urban waste as a source of nutrients in agriculture is an economic alternative for discarding this material. However, due to the diversity of materials that compose this waste, long term studies on its effects on soil chemical attributes and crop yield are necessary. This study aimed at evaluating the potential of urban waste compost (UWC) as a fertilizer for sunflower and maize crops, as well as its effects on the chemical attributes of an Oxisol. A field experiment, with UWC doses of $0 \mathrm{Mg} \mathrm{ha}^{-1}, 10 \mathrm{Mg} \mathrm{ha}^{-1}, 20 \mathrm{Mg} \mathrm{ha}^{-1}$, $30 \mathrm{Mg} \mathrm{ha}^{-1}$ and $40 \mathrm{Mg} \mathrm{ha}^{-1}$ and mineral fertilization according to the recommendation for each crop, was carried out. The results showed an increase in soil $\mathrm{pH}$ from 6 to 6.5 , with the UWC application. The soil potential acidity decreased linearly from $3.0 \mathrm{cmol}_{\mathrm{c}} \mathrm{dm}^{-3}$ to $2.4 \mathrm{cmol} \mathrm{dm}_{\mathrm{c}}^{-3}$, contributing to the SMP index increase, what reflected on the increase of the soil cation exchange capacity. The bases saturation increased from $77 \%$ to $85 \%$, mainly due to the increase in calcium and magnesium levels. The use of UWC resulted in sunflower grain yield similar to that for mineral fertilization, at $10 \mathrm{Mg} \mathrm{ha}^{-1}, 20 \mathrm{Mg} \mathrm{ha}^{-1}$ and $30 \mathrm{Mg} \mathrm{ha}^{-1}$, being significantly higher at $40 \mathrm{Mg} \mathrm{ha}^{-1}$. The maize grain yield at or above $20 \mathrm{Mg} \mathrm{ha}^{-1}$ of UWC did not differ from the mineral fertilization. The UWC presented potential to replace the mineral fertilization for sunflower and maize crops.
\end{abstract}

KEY-WORDS: Zea mays L.; Helianthus annuus L.; organic fertilization; plant nutrition; soil acidity.

\section{INTRODUÇÃO}

A utilização de fontes alternativas de nutrientes na agricultura vem sendo investigada por diversos autores, principalmente em função da redução nos custos de produção. Dentre as várias fontes orgânicas com potencial para utilização na agricultura destacam-se o lodo de esgoto (Lobo \& Grassi Filho

\section{RESUMO}

A utilização de resíduos urbanos compostados como fonte de nutrientes na agricultura é uma alternativa econômica de descarte deste material. Todavia, devido à diversidade dos materiais que compõem estes resíduos, há a necessidade de estudos constantes sobre os efeitos de sua utilização nas propriedades químicas do solo e na produtividade das culturas. Objetivou-se avaliar o potencial fertilizante de um composto de lixo urbano (CLU) nas culturas de girassol e milho e seu efeito nas propriedades químicas de um Latossolo Vermelho. Realizouse experimento de campo com tratamentos compostos por doses de $0 \mathrm{Mg} \mathrm{ha}^{-1}, 10 \mathrm{Mg} \mathrm{ha}^{-1}, 20 \mathrm{Mg} \mathrm{ha}^{-1}, 30 \mathrm{Mg} \mathrm{ha}^{-1}$ e $40 \mathrm{Mg} \mathrm{ha}^{-1}$ de CLU e adubação mineral conforme a recomendação de cada cultura. Os resultados indicaram aumento no $\mathrm{pH}$ do solo de 6 para 6,5 , com a adição do CLU. A acidez potencial do solo diminuiu linearmente de $3,0 \mathrm{cmol}_{\mathrm{c}} \mathrm{dm}^{-3}$ para $2,4 \mathrm{cmol}_{\mathrm{c}} \mathrm{dm}^{-3}$, contribuindo para o acréscimo no índice SMP, o que refletiu no aumento da capacidade de troca de cátions do solo. A saturação por bases aumentou de $77 \%$ para $85 \%$, devido, principalmente, ao acréscimo nos teores de cálcio e magnésio. O CLU proporcionou produtividade de grãos de girassol semelhante à da adubação mineral, nas doses de $10 \mathrm{Mg} \mathrm{ha}^{-1}, 20 \mathrm{Mg} \mathrm{ha}^{-1}$ e $30 \mathrm{Mg} \mathrm{ha}^{-1}$, sendo que, na dose de $40 \mathrm{Mg} \mathrm{ha}^{-1}$, foi significativamente superior. A produtividade de grãos de milho em doses iguais ou superiores a $20 \mathrm{Mg} \mathrm{ha}^{-1}$ de CLU não diferiu da adubação mineral. O CLU apresentou potencial fertilizante, podendo substituir a adubação mineral nas culturas de girassol e milho.

PALAVRAS-CHAVE: Zea mays L.; Helianthus annuus L.; adubação orgânica; nutrição de plantas; acidez do solo.

2007, Ribeirinho et al. 2012), dejetos líquidos de suínos (Ceretta et al. 2010, Castoldi et al. 2011, Sartor et al. 2012), biossólidos de fibras e resinas de polietileno tereftalato (Trannin et al. 2005), resíduos líquidos de efluentes da agroindústria de carnes (Moraes et al. 2012), dejetos bovinos e cama de frango (Guareschi et al. 2013). Entretanto, estudos com composto de lixo urbano para uso na agricultura (Kray et al.

1. Trabalho recebido em mar./2013 e aceito para publicação em ago./2013 (nº registro: PAT 23079).

2. Universidade Federal de Santa Maria (UFSM), Frederico Westphalen, RS, Brasil.E-mails: tiago.strojaki@hotmail.com, vanderlei@ufsm.br, andre.s.1992@hotmail.com, clovisdaros@ufsm.br.

3. Universidade Federal do Rio Grande do Sul (UFRGS), Faculdade de Agronomia, Departamento de Solos, Porto Alegre, RS, Brasil.E-mail: moacir.tuzzin@gmail.com. 
2011, Krob et al. 2011) têm sido pouco conduzidos. Porém, faz-se necessário encontrar alternativas para a aplicação de resíduos orgânicos, minimizando o impacto ambiental de disposições inadequadas destes resíduos no solo.

Os compostos orgânicos podem disponibilizar nutrientes como o N, P e K, para plantas e micro-organismos (Kray et al. 2011), melhorando os atributos químicos (Krob et al. 2011) e físicos do solo (Sampaio et al. 2012), pela adição de matéria orgânica (Nogueira et al. 2011), além de proporcionar maior reciclagem de nutrientes no solo pelas culturas, em relação ao uso da adubação mineral (Melo et al. 2011). Portanto, a verificação do potencial fertilizante de compostos de lixo urbano em áreas agrícolas poderá incentivar a destinação e utilização correta de resíduos orgânicos (Krob et al. 2011). Por meio da aplicação destes materiais ao solo, busca-se igualar, ou mesmo superar, a produtividade de grãos das culturas obtida com a utilização de fertilizantes químicos, possibilitando reduzir custos produtivos.

Conforme Krob et al. (2011), a maior parte dos estudos que visam a avaliar a melhoria nas propriedades químicas do solo, em função da adição de compostos de lixo urbano, restringe-se a experimentos em vasos, em casa-de-vegetação, sendo insuficientes para a realização de recomendações seguras sobre a correta utilização destes resíduos. Todavia, aplicações sucessivas de composto de lixo urbano em doses mais elevadas do que a necessidade das plantas podem causar efeitos negativos ao solo e às plantas (Krob et al. 2011), sendo que a utilização de compostos orgânicos, como compostos de lixo urbano, em solos agrícolas, pode ser uma opção viável para reduzir o impacto ambiental da disposição destes produtos (Kray et al. 2011). Portanto, são necessários mais estudos, em diferentes condições de clima e solo e em condições de campo, para avaliar o efeito de aplicações sucessivas e doses elevadas de composto de lixo urbano nas propriedades químicas do solo (Krob et al. 2011).

Com base nessas considerações, objetivou-se avaliar o potencial fertilizante de um composto de lixo urbano, nas culturas de girassol e milho, e seu efeito nas propriedades químicas de um Latossolo Vermelho de textura muito argilosa.

\section{MATERIAL E MÉTODOS}

O trabalho foi conduzido em área experimental da Universidade Federal de Santa Maria, Campus de Frederico Westhalen, RS $\left(27^{\circ} 23^{\prime} \mathrm{S}, 53^{\circ} 25^{\prime} \mathrm{W}\right.$ e altitude de $480 \mathrm{~m}$ ). O clima desta região, segundo a classificação de Köppen, é subtropical úmido, tipo Cfa. O solo da área experimental, manejado sob sistema plantio direto (SPD) desde 2000, é classificado como Latossolo Vermelho aluminoférrico (LVaf) (Santos et al. 2013) e Rhodic Hapludox (SSS 2010), com textura muito argilosa ( $650 \mathrm{~g} \mathrm{~kg}^{-1}$ de argila). Os atributos químicos, na camada $0,0-0,10 \mathrm{~m}$, antes da implantação do experimento, estão disponíveis na Tabela 1.

O delineamento experimental foi de blocos completos casualizados, com quatro repetições, em parcelas de 13,6 $\mathrm{m}^{2}$ (4,0 m x 3,4 m). Foram utilizados seis tratamentos, que consistiram das doses: (i) $0 \mathrm{Mg} \mathrm{ha}^{-1}$, (ii) $10 \mathrm{Mg} \mathrm{ha}^{-1}$, (iii) $20 \mathrm{Mg} \mathrm{ha}^{-1}$, (iv) $30 \mathrm{Mg} \mathrm{ha}^{-1} \mathrm{e}$ (v) $40 \mathrm{Mg} \mathrm{ha}^{-1}$ de composto de lixo urbano (CLU), com base em massa seca, e (vi) testemunha com adubação mineral com nitrogênio $(\mathrm{N})$, fósforo (P) e potássio (K) (CQFS-RS/SC 2004), para as culturas do milho, girassol e aveia preta.

As doses de CLU foram definidas em base volumétrica e convertidas em base de massa, em função da densidade de CLU de $0,4 \mathrm{Mg} \mathrm{m}^{-3}$, portanto, independentemente da cultura, foram utilizadas as mesmas doses de CLU.

O CLU foi proveniente do Consórcio Intermunicipal de Gestão de Resíduos Sólidos do município de Seberi (RS), onde se realiza a compostagem após

Tabela 1. Atributos químicos da camada superficial do solo (0,0-0,10 m), antes da implantação do experimento (Frederico Westhalen, RS, 2013).

\begin{tabular}{|c|c|c|c|c|c|c|c|c|c|c|c|c|c|}
\hline \multirow{2}{*}{ pH água } & \multirow{2}{*}{ SMP } & $\mathrm{P}$ & $\mathrm{K}$ & $\mathrm{Al}$ & $\mathrm{Ca}$ & $\mathrm{Mg}$ & $\mathrm{Cu}$ & $\mathrm{Zn}$ & $\mathrm{H}+\mathrm{Al}$ & $\mathrm{CTC}_{\mathrm{pH} 7}$ & $\mathrm{MO}$ & $\mathrm{V}$ & Argila \\
\hline & & \multicolumn{2}{|c|}{$\mathrm{mg} \mathrm{dm}{ }^{-3}$} & & & & $\mathrm{cmo}$ & $m^{-3}-$ & & & \multicolumn{2}{|c|}{$-\%$} & $\mathrm{~g} \mathrm{~kg}^{-1}$ \\
\hline 5,1 & 6,2 & 7,6 & 280 & 0,2 & 5,5 & 1,6 & 5,8 & 1,8 & 3,2 & 11,3 & 2,1 & 69 & 650 \\
\hline
\end{tabular}

P: fósforo disponível; $\mathrm{K}$ : potássio disponível; $\mathrm{Al}$ : alumínio trocável; Ca: cálcio trocável; $\mathrm{Mg}$ : magnésio trocável; $\mathrm{Cu}$ : cobre disponível; Zn: zinco disponível; $\mathrm{H}+\mathrm{Al}$ : acidez potencial; $\mathrm{CTC}_{\mathrm{pH}}$ : capacidade de troca de cátions em $\mathrm{pH}$ 7; MO: matéria orgânica; V: saturação por bases. 
Tabela 2. Caracterização química do composto de lixo urbano (Frederico Westhalen, RS, 2013).

\begin{tabular}{|c|c|c|c|c|c|c|c|c|c|}
\hline \multirow{2}{*}{ pH em água } & $\mathrm{N}^{*}$ & $\mathrm{P} * *$ & $\mathrm{~K}^{* *}$ & $\mathrm{Ca}^{* *}$ & $\mathrm{Mg} * *$ & $\mathrm{~S} * *$ & $\mathrm{Mn} * *$ & $\mathrm{Zn} * *$ & $\mathrm{Cu}^{* *}$ \\
\hline & \multicolumn{6}{|c|}{$\mathrm{g} \mathrm{kg}^{-1}$} & \multicolumn{3}{|c|}{$\mathrm{mg} \mathrm{kg}^{-1}$} \\
\hline 7,2 & 9,7 & 5,0 & 4,4 & 30,1 & 4,0 & 5,4 & 775,1 & 526,8 & 250,1 \\
\hline
\end{tabular}

* Teor disponível (Tedesco et al. 1995). ** Teores totais, pela técnica de Fluorescência de Raios-X por Energia Dispersiva (Wastowski et al. 2010).

a separação do resíduo orgânico. Na Tabela 2, estão especificadas as características químicas, determinadas por Espectrometria de Fluorescência de Raios-X por Energia Dispersiva (Wastowski et al. 2010), o pH em água e o teor de $\mathrm{N}$ (Tedesco et al. 1995).

$\mathrm{Na}$ área, foi utilizado um sistema de rotação de culturas com girassol (safra de verão 2009/2010), aveia preta (safra de inverno de 2010) e milho (safra de verão 2010/2011). As doses de CLU foram aplicadas manualmente, na superfície do solo, antes da semeadura das culturas do girassol (27/07/2009), aveia preta (15/05/2010) e milho (10/09/2010).

No tratamento com adubação mineral, foram aplicados, para a cultura do girassol, $10 \mathrm{~kg} \mathrm{ha}^{-1} \mathrm{de}$ $\mathrm{N}$ e $30 \mathrm{~kg} \mathrm{ha}^{-1}$ de $\mathrm{P}_{2} \mathrm{O}_{5}$ na semeadura e $50 \mathrm{~kg} \mathrm{ha}^{-1} \mathrm{de}$ $\mathrm{N}$ em cobertura, para uma expectativa de produtividade de grãos de 2,0 $\mathrm{Mg} \mathrm{ha}^{-1}$. Na cultura do milho, foram aplicados $20 \mathrm{~kg} \mathrm{ha}^{-1}$ de N, $45 \mathrm{~kg} \mathrm{ha}^{-1} \mathrm{de}_{2} \mathrm{O}_{5} \mathrm{e}$ $30 \mathrm{~kg} \mathrm{ha}^{-1} \mathrm{de} \mathrm{K}_{2} \mathrm{O}$ na semeadura e $70 \mathrm{~kg} \mathrm{ha}^{-1}$ de $\mathrm{N}$ em cobertura, para uma expectativa de produtividade de grãos de $6,0 \mathrm{Mg} \mathrm{ha}^{-1}$. Na cultura da aveia preta, utilizada somente para cobertura do solo, foram aplicados $31 \mathrm{~kg} \mathrm{ha}^{-1}$ de P, $12 \mathrm{~kg} \mathrm{ha}^{-1}$ de $\mathrm{K}$ e $56 \mathrm{~kg} \mathrm{ha}^{-1}$ de N, para uma expectativa de rendimento de $5 \mathrm{Mg} \mathrm{ha}^{-1} \mathrm{de}$ massa seca. Para todas as fertilizações químicas com $\mathrm{N}$, P e K, foram utilizados, como fontes, os fertilizantes químicos ureia, superfosfato triplo e cloreto de potássio, respectivamente. $\mathrm{Na}$ Tabela 3, estão especificados os teores totais de nutrientes para os três cultivos.

A semeadura do girassol foi realizada no dia 10/12/2009, utilizando-se o híbrido simples HLA-203 Clearfield. O espaçamento entre as linhas foi de $0,8 \mathrm{~m}$ e a população obtida de 30 mil plantas ha ${ }^{-1}$. Na sequência do sistema de rotação de culturas, utilizou-se, para cobertura do solo, a cultura da aveia preta, semeada a lanço no dia 29/05/2010. Posteriormente, foi utilizada a cultura do milho (cultivar AS $1555 \mathrm{YG}$ ), semeada em 21/10/2010, com espaçamento de $0,40 \mathrm{~m}$ entre as linhas e população de 75 mil plantas ha-1. A colheita do girassol e do milho foram realizadas em 19/03/2010 e 16/02/2011, respectivamente.
A precipitação e a temperatura média do ar, durante os ciclos das culturas do girassol e do milho, foram obtidas da Estação Meteorológica Automática de Frederico Westphalen (Figura 1).

$\mathrm{Na}$ avaliação das culturas, quantificou-se a produtividade de grãos de girassol e milho, diâmetro médio de capítulos de girassol e massa de mil grãos de

Tabela 3. Aportes anuais de nutrientes aplicados com o composto de lixo urbano e adubação mineral (Frederico Westhalen, RS, 2013).

\begin{tabular}{crcr}
\hline Dose de CLU & $\mathrm{N}$ & $\mathrm{P}$ & $\mathrm{K}$ \\
\hline $\mathrm{Mg} \mathrm{ha}^{-1}$ & \multicolumn{4}{c}{ Composto de lixo urbano* } \\
\hline \multicolumn{4}{c}{$\mathrm{kg} \mathrm{ha}^{-1}$ urbar } \\
0 & 0 & 0 & 0 \\
10 & 97 & 50 & 44 \\
20 & 194 & 100 & 88 \\
30 & 291 & 150 & 132 \\
40 & 388 & 200 & 176 \\
\hline Cultura & \multicolumn{4}{|}{ Adubação química } \\
\hline Girassol & 72 & 41 & 34 \\
Aveia preta & 83 & 77 & 52 \\
Milho & 56 & 31 & 12 \\
\hline
\end{tabular}

* Doses aplicadas antes da semeadura de cada uma das culturas (girassol, aveia preta e milho).

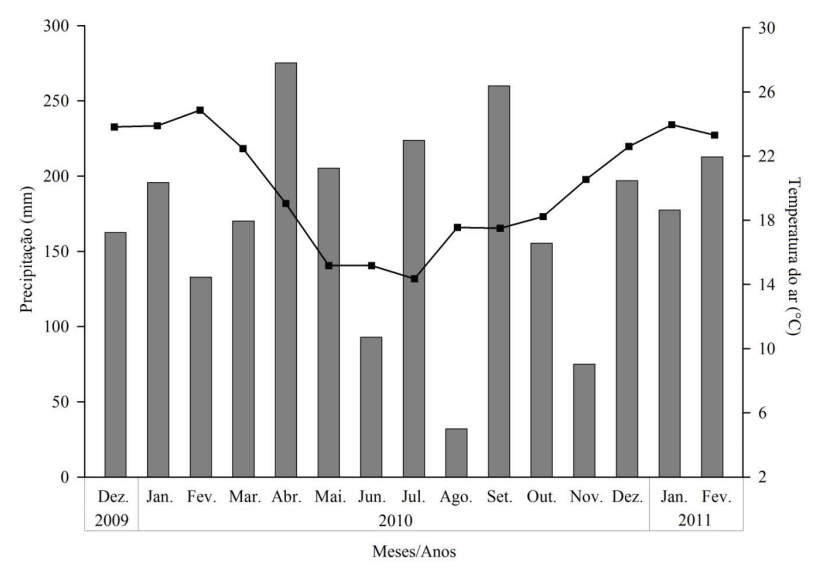

Figura 1. Precipitação e temperatura média do ar, durante os ciclos das culturas do girassol (safra 2009/2010) e do milho (safra 2010/2011) (Frederico Westhalen, RS). 
milho. A produtividade de grãos foi determinada no centro das parcelas (eliminando-se 1,0 m de bordadura, em todos os lados da parcela), em uma área útil de 7,2 $\mathrm{m}^{2}(3,0 \mathrm{~m} \times 2,4 \mathrm{~m})$, atendendo, assim, ao tamanho ótimo de parcela para girassol (Lorentz et al. 2010) e milho (Cargnelutti Filho et al. 2011). Para ambas as culturas, a umidade dos grãos foi corrigida para 13\% (Brasil 2009). A massa de mil grãos do milho foi determinada em oito repetições de 100 aquênios e extrapolada para peso de mil grãos (Brasil 2009). O diâmetro de capítulo do girassol foi mensurado por uma linha imaginária no centro do capítulo (Moraes et al. 2012).

Após a realização da colheita do milho (safra 2010/2011), foram coletadas amostras deformadas de solo, na camada de 0,0-0,1 m, para avaliação dos seguintes atributos químicos: $\mathrm{pH}$ em água, acidez potencial $(\mathrm{H}+\mathrm{Al})$, fósforo $(\mathrm{P})$, potássio $(\mathrm{K})$, cálcio $(\mathrm{Ca})$, magnésio $(\mathrm{Mg})$, capacidade de troca de cátions efetiva (CTC efetiva) $(\mathrm{K}+\mathrm{Ca}+$ $\mathrm{Mg}$ ), capacidade de troca de cátions potencial (CTC potencial) (CTC efetiva $+(\mathrm{H}+\mathrm{Al}))$, saturação por bases e índice SMP (Shoemaker, McLean e Pratt), de acordo com metodologias propostas por Tedesco et al. (1995).

Os resultados foram submetidos à análise de variância e, quando significativos, para os fatores qualitativos (comparação das doses de CLU com a adubação mineral) compararam-se as médias pelo teste de Dunnett, e para os fatores quantitativos (doses de CLU) realizou-se análise de regressão, ambos a $5 \%$. As análises foram realizadas por meio do programa computacional SAS versão 8.0.

\section{RESULTADOS E DISCUSSÃO}

Os atributos do solo diferiram em função das doses de CLU aplicadas (Tabela 4). O pH do solo aumentou linearmente de 6,0 para 6,5 , em função do aumento nas doses de $0 \mathrm{Mg} \mathrm{ha}^{-1}$ para $40 \mathrm{Mg} \mathrm{ha}^{-1}$ de CLU, o que, provavelmente, está relacionado à alcalinidade do CLU $(\mathrm{pH}=7,2)$ aplicado em solo ácido $(5,1)$. Incrementos nos valores de $\mathrm{pH}$ também foram observados com a adição de CLU a um Argissolo Vermelho-Amarelo distrófico, fato atribuído à presença de ânions orgânicos solúveis $\left(\mathrm{R}^{-\mathrm{COO}^{-} \mathrm{e}}\right.$ R-O-) em resíduos orgânicos, que, ao serem liberados, podem adsorver $\mathrm{H}^{+}$da solução do solo, por meio de reação de troca, envolvendo, principalmente, íons $\mathrm{Ca}^{2+}$ (Mantovani et al. 2005).

Esses incrementos nos valores de $\mathrm{pH}$ favoreceram alterações na disponibilidade de íons no solo e podem ter ocorrido devido à mineralização do carbono e subsequente produção de íons $\mathrm{OH}^{-}$, bem como à introdução de cátions básicos, como

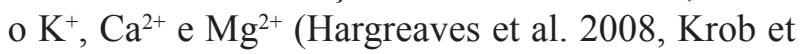
al. 2011).

Valores de $\mathrm{pH}$ mais próximos a 7,0 proporcionam maiores disponibilidades de $\mathrm{P}\left(\mathrm{H}_{2} \mathrm{PO}^{4-}\right)$, uma vez que, sob condições ácidas, ocorre reação do $\mathrm{H}_{2} \mathrm{PO}^{4-}$ com as formas iônicas do $\mathrm{Fe}$ e $\mathrm{Al}$, formando compostos de baixa solubilidade, além do fato de que, em solos argilosos com altos teores de óxidos de $\mathrm{Fe}$ e Al, o incremento nos valores de $\mathrm{pH}$ favorece a redução na adsorção do ânion $\mathrm{H}_{2} \mathrm{PO}^{4-}$ pelos óxidos de Fe e Al, disponibilizando-os para a solução do solo (Mantovani et al. 2005).

Tabela 4. Atributos químicos e equações de regressão, para as doses do composto de lixo urbano (CLU), em um Latossolo Vermelho aluminoférrico $^{(1)}($ Frederico Westhalen, RS, 2013).

\begin{tabular}{|c|c|c|c|c|c|c|c|c|}
\hline \multirow{2}{*}{ Atributo } & \multirow{2}{*}{$\mathrm{NPK}^{(1)}$} & \multicolumn{5}{|c|}{ Doses de CLU $\left(\mathrm{Mg} \mathrm{ha}^{-1}\right)$} & \multirow{2}{*}{$\begin{array}{l}\text { Regressão das } \\
\text { doses de CLU }\end{array}$} & \multirow{2}{*}{$\mathrm{R}^{2}$} \\
\hline & & 0 & 10 & 20 & 30 & 40 & & \\
\hline pH em água & 5,9 & $6,0^{\mathrm{ns}}$ & $6,3^{\text {ns }}$ & $6,4^{\mathrm{ns}}$ & $6,2^{\mathrm{ns}}$ & $6,5^{*}$ & $\hat{y}=6,07+0,009^{* * x}$ & 0,57 \\
\hline $\mathrm{H}+\mathrm{Al}\left(\mathrm{cmol}_{\mathrm{c}} \mathrm{dm}^{-3}\right)$ & 3,5 & $3,0^{\text {ns }}$ & $2,7 *$ & $2,6^{*}$ & $2,7 *$ & $2,2 *$ & $\hat{y}=2,95-0,015^{* * x}$ & 0,78 \\
\hline Índice SMP & 6,2 & $6,3^{\mathrm{ns}}$ & $6,4^{*}$ & $6,5^{*}$ & $6,4^{*}$ & $6,6^{*}$ & $\hat{\mathrm{y}}=6,35+0,005^{* *} \mathrm{x}$ & 0,77 \\
\hline CTC efetiva $\left(\mathrm{cmol}_{\mathrm{c}} \mathrm{dm}^{-3}\right)$ & 8,5 & $9,6^{\mathrm{ns}}$ & $11,1^{*}$ & $11,2 *$ & $11,6^{*}$ & $13,3^{*}$ & $\hat{\mathrm{y}}=9,79+0,079 * * \mathrm{x}$ & 0,89 \\
\hline CTC potencial $\left(\mathrm{cmol}_{\mathrm{c}} \mathrm{dm}^{-3}\right)$ & 12,0 & $12,8^{\mathrm{ns}}$ & $13,8^{\mathrm{ns}}$ & $13,8^{\mathrm{ns}}$ & $14,3^{\mathrm{ns}}$ & $15,6^{*}$ & $\hat{\mathrm{y}}=12,84+0,060^{* *} \mathrm{x}$ & 0,90 \\
\hline Saturação por bases ${ }^{(2)}(\%)$ & 70,7 & $76,3^{\mathrm{ns}}$ & $80,0^{*}$ & $81,3^{*}$ & $81,0 *$ & $85,7^{*}$ & $\hat{\mathrm{y}}=76,93+0,197 * * \mathrm{x}$ & 0,87 \\
\hline $\mathrm{Ca}\left(\mathrm{cmol}_{\mathrm{c}} \mathrm{dm}^{-3}\right)$ & 5,2 & $6,2^{\text {ns }}$ & $6,7^{\mathrm{ns}}$ & $6,4^{\mathrm{ns}}$ & $6,8^{\text {ns }}$ & $8,8^{*}$ & $\hat{\mathrm{y}}=5,95+0,052 * * \mathrm{x}$ & 0,63 \\
\hline $\mathrm{Mg}\left(\mathrm{cmol}_{\mathrm{c}} \mathrm{dm}^{-3}\right)$ & 3,2 & $3,2^{\mathrm{ns}}$ & $3,2^{\text {ns }}$ & $3,0^{\text {ns }}$ & $3,4^{\mathrm{ns}}$ & $4,3 *$ & $\hat{\mathrm{y}}=3,30-0,045^{*} * \mathrm{x}+0,002 * * \mathrm{x}^{2}$ & 0,96 \\
\hline $\mathrm{P}\left(\mathrm{mg} \mathrm{dm}^{-3}\right)$ & 4,5 & $4,0^{\text {ns }}$ & $6,0^{\text {ns }}$ & $11,4^{\mathrm{ns}}$ & $17,8^{\mathrm{ns}}$ & $15,5^{\mathrm{ns}}$ & $\overline{\mathrm{y}}=10,94^{\mathrm{ns}}$ & - \\
\hline $\mathrm{K}\left(\mathrm{mg} \mathrm{dm}^{-3}\right)$ & 82,7 & $122,7^{\mathrm{ns}}$ & $225,3^{\mathrm{ns}}$ & $168,0^{\mathrm{ns}}$ & $109,3^{\mathrm{ns}}$ & $118,7^{\mathrm{ns}}$ & $\overline{\mathrm{y}}=148,80^{\mathrm{ns}}$ & - \\
\hline
\end{tabular}

${ }^{(1)}$ Tratamento testemunha, em que doses de composto de lixo urbano são comparadas à adubação mineral $(\mathrm{NPK})$; ${ }^{(2)} \mathrm{Saturação} \mathrm{por} \mathrm{bases}=((\mathrm{Ca}+\mathrm{Mg}+\mathrm{K}+\mathrm{Na}) / \mathrm{CTC}$ potencial)*100. * Significativo pelo teste de Dunnett $(\mathrm{p}<0,05)$; ** Significativo pelo teste $\mathrm{t}(\mathrm{p}<0,05)$; ${ }^{\text {ns }}$ Não significativo. 
A acidez potencial foi reduzida linearmente, em função do incremento nas doses de CLU (Tabela 4). Para a testemunha sem adubação (zero), a acidez potencial foi de $3,0 \mathrm{cmol}_{\mathrm{c}} \mathrm{dm}^{-3}$, reduzindo-se para 2,4 $\mathrm{cmol}_{\mathrm{c}} \mathrm{dm}^{-3}$, na dose de $40 \mathrm{Mg} \mathrm{ha}^{-1}$. A redução na acidez potencial do solo contribuiu para o acréscimo nos valores do índice SMP, demonstrando que este CLU pode apresentar potencial de redução da acidez do solo. Isto refletiu em aumento na saturação por bases de $77 \%$ para $85 \%$, para as doses de $0 \mathrm{Mg} \mathrm{ha}^{-1}$ e $40 \mathrm{Mg} \mathrm{ha}^{-1}$, respectivamente.

Santos et al. (2004) observaram reduções na acidez potencial, em função da adição de composto de cama de frango, em Latossolo Vermelho, e atribuíram o aumento nos valores de $\mathrm{pH}$ associados ao aumento nos teores dos cátions trocáveis do solo. Guedes et al. (2006) observaram, em aplicação de biossólido de esgoto em Latossolo Vermelho-Amarelo com textura média, que, a partir de doses de $40 \mathrm{Mg} \mathrm{ha}^{-1}$ de biossólido, a acidez potencial foi reduzida em mais de cinco vezes, em relação ao tratamento sem a utilização do biossólido.

Aumentos significativos de $\mathrm{Ca}$ e Mg também foram observados com o incremento nas doses de CLU (Tabela 4). Os teores de Ca foram incrementados linearmente de 6,0 para 8,0, com a utilização das doses de $0 \mathrm{Mg} \mathrm{ha}^{-1} \mathrm{e} 40 \mathrm{Mg}^{-1}$ de CLU, respectivamente. Os teores de $\mathrm{Mg}$ foram incrementados de 3,3 para 4,2, em função do uso das doses de $0 \mathrm{Mg} \mathrm{ha}^{-1}$ e $40 \mathrm{Mg} \mathrm{ha}^{-1}$ de CLU, respectivamente. Portanto, os dois cátions básicos $(\mathrm{Ca}$ e $\mathrm{Mg}$ ) tiveram seus teores no solo aumentados em 1,4 vezes, em função da maior dose de CLU (40 Mg ha-1 $)$, demonstrando, assim, que este composto apresenta potencial de disponibilização de nutrientes para as plantas.

Os teores de $\mathrm{Ca}$ e $\mathrm{Mg}$ foram os principais responsáveis pelo incremento nos valores da saturação por bases, pois os teores de K não foram alterados em função da adição de CLU ao solo (Tabela 4). Incrementos nos teores de $\mathrm{Ca}$ e $\mathrm{Mg}$, em função da aplicação de CLU, foram observados em um Argissolo Vermelho de textura média (Krob et al. 2011). Estes autores afirmam que aplicações anuais de até $80 \mathrm{Mg} \mathrm{ha}^{-1} \mathrm{de}$ CLU podem ser consideradas adequadas para melhorar ou manter as propriedades químicas do solo.

Os valores de CTC efetiva e CTC potencial aumentaram linearmente, em função do incremento nas doses de CLU (Tabela 4). Isto decorre dos incrementos nos teores dos cátions $(\mathrm{Ca}$ e $\mathrm{Mg})$, o que favorece melhorias nas condições de troca de cátions do solo. Estes resultados concordam com os obtidos por Abreu Júnior et al. (2001), os quais avaliaram a aplicação de $60 \mathrm{Mg} \mathrm{ha}^{-1}$ de CLU, em 21 solos ácidos e 5 alcalinos, e observaram que houve aumentos nos valores de CTC potencial nos solos ácidos, em função do acréscimo de cargas negativas provenientes da matéria orgânica contida no CLU.

Os incrementos na CTC efetiva do solo estão relacionados com o aumento nos valores de $\mathrm{pH}$ do solo, pois os grupos funcionais do material orgânico são dependentes de $\mathrm{pH}$ e, em pH superior a 3,5 (valor do PCZ), predominam cargas negativas nestes grupos, graças à dissociação do $\mathrm{H}^{+}$e formação de água (Pavinato \& Roselem 2008).

$\mathrm{O}$ aumento na quantidade de cargas negativas no solo resultou no aumento da capacidade de troca de cátions nos sítios de adsorção, potencializando as reações de complexos de esfera externa entre os coloides do solo e os cátions básicos, os quais ficam facilmente disponibilizados para a solução do solo (Sposito 1989, Silva \& Bohnen 2006).

As doses de CLU não contribuíram, significativamente, para aumentar os teores de $\mathrm{K}$ e $\mathrm{P}$ no solo. Os teores de $\mathrm{P}$ apresentaram variação de 4,0-17,8 $\mathrm{mg} \mathrm{dm}^{-3}$, para as doses de $0 \mathrm{Mg} \mathrm{ha}^{-1} \mathrm{e}$ $30 \mathrm{Mg} \mathrm{ha}^{-1}$ de CLU, respectivamente, porém, não houve diferença significativa. Ruppenthal \& Castro (2005), utilizando CLU com e sem adubação mineral, em Latossolo Vermelho eutroférrico de textura muito argilosa, observaram que não houve incrementos nos teores de $\mathrm{Pe} \mathrm{K}$, quando foi utilizado CLU na ausência de adubação mineral, porém, doses de $10 \mathrm{Mg} \mathrm{ha}^{-1}$ de CLU foram suficientes para proporcionar condições adequadas de nutrição, desenvolvimento e produção de bulbos na cultura do gladíolo (Gladiolus glandiflorus), a qual é uma importante espécie de flor produzida no Brasil.

A adubação mineral, em comparação com a testemunha sem aplicação de CLU, não alterou nenhum atributo químico do solo (Tabela 4). Isto, provavelmente, ocorreu devido ao fato de a aplicação de nutrientes ter ocorrido em função da necessidade nutricional das culturas somente como adubação de reposição (CQFS-RS/SC 2004), pois a opção de adubar pela reposição é indicada quando os teores de nutrientes no solo estão na faixa "muito alto" (CQFS-RS/SC 2004) (Tabela 1). Portanto, estas doses de adubação mineral não foram suficientes para alterar os níveis de nutrientes no solo, em relação ao tratamento sem adubação. 
Silva et al. (2012) avaliaram a utilização de diferentes fontes de nutrientes (cama de frango, cama de peru, dejetos suínos e fertilização mineral), em um Latossolo Vermelho distrófico de textura média, em área de Cerrado sob pastagem degradada, e observaram que, na camada de 0,0-0,20 m, nas áreas com adubações orgânicas, houve incrementos nos teores de $\mathrm{P}$ e K, porém, na área com fertilização mineral, houve acidificação do solo (redução nos valores de pH). Isto ocorreu em função da hidrólise da ureia e subsequente nitrificação da amônia, extração de potássio e liberação de $\mathrm{H}^{+}$pelas raízes das plantas (Silva et al. 2012).

A produtividade de grãos de girassol aumentou linearmente com a aplicação de CLU (Tabela 5), com acréscimo de 7,3 $\mathrm{kg} \mathrm{ha}^{-1}$ por Mg de CLU aplicado. Destaca-se que não houve diferenças significativas de produtividade de grãos entre a adubação mineral e as doses de CLU até $30 \mathrm{Mg} \mathrm{ha}^{-1}$ (Tabela 5). Entretanto, foram observados incrementos na produtividade de grãos de girassol na dose de $40 \mathrm{Mg} \mathrm{ha}^{-1}$ de CLU, em relação à adubação mineral (Tabela 5). Isto demonstra que o CLU pode substituir a adubação mineral na cultura do girassol, e que doses de CLU de $40 \mathrm{Mg} \mathrm{ha}^{-1}$ proporcionam incrementos na produtividade de grãos de girassol, em Latossolo Vermelho.

A cultura do girassol apresenta ótimos desempenhos produtivos, quando submetida à utilização de fontes orgânicas. Moraes et al. (2012) avaliaram o desempenho produtivo de girassol sob fertilização com resíduos líquidos de efluentes da agroindústria de carnes e adubação mineral, em Latossolo Vermelho com textura muito argilosa, e observaram que esta fonte orgânica de nutrientes possibilitou substituir a adubação mineral, sem causar prejuízos ao potencial produtivo da cultura.

Ribeirinho et al. (2012) utilizaram lodo de esgoto como fonte de nutrientes para a cultura do girassol, em Latossolo Vermelho eutroférrico de textura argilosa, e observaram que o lodo de esgoto foi viável para a cultura, a qual apresentou produtividade equivalente à da adubação mineral.

Silva et al. (2010) também avaliaram a produtividade de grãos de girassol, em função da utilização de doses de lodo de esgoto desidratado $\left(0 \mathrm{Mg} \mathrm{ha}^{-1}\right.$, 6,25 Mg ha' ${ }^{-1}, 12,5 \mathrm{Mg} \mathrm{ha}^{-1}$ e 18,5 $\mathrm{Mg} \mathrm{ha}^{-1}$ ) e adubação mineral, em Cambissolo Háplico, e observaram que a adubação mineral pode ser substituída pelo lodo de esgoto, sem que ocorram perdas produtivas na cultura.

O diâmetro de capítulo do girassol não foi influenciado pelas doses de CLU, em relação à adubação mineral (Tabela 5), demonstrando, assim, que, independentemente da fonte de nutrientes utilizada, observou-se diâmetro médio do capítulo de girassol de $18,6 \mathrm{~cm}$. Isto indica que a adubação mineral pode ser substituída pelo CLU, nestas condições de solo e clima, sem que ocorram alterações no diâmetro dos capítulos do girassol.

O diâmetro do capítulo do girassol tem relação direta com o número potencial de aquênios (Lobo \& Grassi Filho 2007), peso de mil aquênios (Pivetta et al. 2012) e com a produtividade de grãos (Silva et al. 2011). Portanto, a manutenção, ou aumento, do diâmetro dos capítulos torna-se um importante componente de rendimento na cultura do girassol.

Moraes et al. (2012), avaliando a utilização de doses de resíduos líquidos de efluentes da agroindústria de carne $\left(25 \mathrm{~m}^{3} \mathrm{ha}^{-1}, 50 \mathrm{~m}^{3} \mathrm{ha}^{-1}, 75 \mathrm{~m}^{3} \mathrm{ha}^{-1}\right.$ e $100 \mathrm{~m}^{3} \mathrm{ha}^{-1}$ ) e adubação mineral, em Latossolo Vermelho, observaram incrementos lineares no diâmetro de capítulos de girassol, em função do aumento nas doses de resíduos orgânico, porém, não houve diferenças de diâmetro dos capítulos, em relação à adubação mineral.

Tabela 5. Componentes de rendimento das culturas de girassol e milho e regressão para as doses de composto de lixo urbano (CLU), em um Latossolo Vermelho aluminoférrico (Frederico Westhalen, RS, 2013).

\begin{tabular}{|c|c|c|c|c|c|c|c|c|}
\hline \multirow{2}{*}{ Variável } & \multirow{2}{*}{$\mathrm{NPK}^{(1)}$} & \multicolumn{5}{|c|}{ Doses de CLU $\left(\mathrm{Mg} \mathrm{ha}^{-1}\right)$} & \multirow{2}{*}{ Regressão das doses de CLU } & \multirow{2}{*}{$\mathrm{R}^{2}$} \\
\hline & & 0 & 10 & 20 & 30 & 40 & & \\
\hline & \multicolumn{8}{|c|}{ Girassol } \\
\hline Produtividade de grãos $\left(\mathrm{Mg} \mathrm{ha}^{-1}\right)$ & 0,69 & $0,59^{\text {ns }}$ & $0,81^{\mathrm{ns}}$ & $0,76^{\mathrm{ns}}$ & $0,82^{\mathrm{ns}}$ & $0,95 *$ & $\hat{y}=0,64+0,0073 * *_{x}$ & 0,79 \\
\hline Diâmetro médio do capítulo $(\mathrm{cm})$ & 17,70 & $18,10^{\mathrm{ns}}$ & $18,50^{\mathrm{ns}}$ & $19,40^{\mathrm{ns}}$ & $18,40^{\mathrm{ns}}$ & $\begin{array}{c}18,60^{\mathrm{ns}} \\
\text { Milho }\end{array}$ & $\overline{\mathrm{y}}=18,6^{\mathrm{ns}}$ & - \\
\hline Produtividade de grãos $\left(\mathrm{Mg} \mathrm{ha}^{-1}\right)$ & 10,44 & $6,17 *$ & $7,46^{*}$ & $8,62^{\mathrm{ns}}$ & $10,23^{\mathrm{ns}}$ & $9,65^{\text {ns }}$ & $\hat{\mathrm{y}}=6,01+0,077^{* *} \mathrm{x}-0,0004^{* *} \mathrm{x}^{2}$ & 0,95 \\
\hline Peso de mil grãos (g) & 305,40 & $287,70^{*}$ & $286,30 * 2$ & $295,30^{\text {ns }} 3$ & $308,10^{\text {ns }}$ & $313,10^{\mathrm{ns}}$ & $\hat{y}=283,60+0,725^{* *} x$ & 0,91 \\
\hline
\end{tabular}


A aplicação de CLU à cultura do milho favoreceu incrementos lineares no peso de mil grãos (Tabela 5), o qual, sob doses iguais ou superiores a $20 \mathrm{Mg} \mathrm{ha}^{-1}$ de CLU, não diferiu da adubação mineral.

Biscaro et al. (2011) avaliaram o efeito da aplicação de $\mathrm{N}$ nas características agronômicas do milho, em Latossolo Vermelho distroférrico, e observaram que a variável massa de mil grãos foi afetada pelas doses de $\mathrm{N}$, indicando que a disponibilidade de nutrientes influencia diretamente no peso dos grãos, e, em consequência, na produtividade de grãos.

Castoldi et al. (2011) avaliaram o desempenho produtivo de milho submetido a diferentes fontes de adubação (mineral, orgânica com biofertilizante de suínos e organomineral), em Latossolo Vermelho eutroférrico de textura argilosa, e constataram que não houve diferença estatística de peso de mil grãos, em função das fontes de adubação. Isto indica que a adubação mineral pode ser substituída por fontes orgânicas, sem que haja perdas nas características agronômicas da cultura.

A produtividade de grãos de milho foi influenciada pelas doses de CLU, sendo que houve incremento quadrático, em função das doses de CLU (Tabela 5). A utilização de doses iguais ou superiores a $20 \mathrm{Mg} \mathrm{ha}^{-1}$ de CLU favoreceu produtividades de grãos iguais às proporcionadas pela adubação mineral (Tabela 5). Isto indica que o CLU disponibilizou quantidades de nutrientes suficientes para a cultura do milho, demonstrando que o CLU apresenta potencial de utilização como fonte de nutrientes, para uso na agricultura.

Sartor et al. (2012) avaliaram a produtividade de grãos de milho sob diferentes doses de dejetos líquidos de suínos e adubação mineral e observaram que o uso de $60 \mathrm{~m}^{3} \mathrm{ha}^{-1}$ de dejetos líquidos de suínos favoreceu a obtenção das maiores produtividades de grãos de milho. Portanto, conforme estes autores, a utilização de adubação orgânica, além de ser uma forma de descarte dos dejetos, contribui para aumento significativo na produtividade de grãos, substituindo, assim, o fertilizante mineral.

\section{CONCLUSÕES}

1. A aplicação sucessiva de composto de lixo urbano promoveu diminuição na acidez potencial e aumentou os valores de $\mathrm{pH}$, índice SMP, capacidade de troca de cátions, saturação por bases e teores de cálcio e magnésio trocáveis do solo.
2. O composto de lixo urbano apresentou potencial fertilizante, podendo substituir a adubação mineral, para o cultivo de girassol e milho em Latossolo Vermelho, nas condições edafoclimáticas da região estudada.

\section{REFERÊNCIAS}

ABREU JÚNIOR, C. H.; MURAOKA, T.; OLIVEIRA, F. C. Cátions trocáveis, capacidade de troca de cátions e saturação por bases em solos brasileiros adubados com composto de lixo urbano. Scientia Agricola, Piracicaba, v. 58 , n. 4 , p. $813-824,2001$.

BISCARO, G. A. et al. Desempenho do milho safrinha irrigado submetido a diferentes doses de nitrogênio via solo e foliar. Revista Agrarian, Dourados, v. 4, n. 11, p. 10-19, 2011.

BRASIL. Ministério da Agricultura, Pecuária e Abastecimento. Regras para análise de sementes. Brasília, DF: MAPA, 2009.

CASTOLDI, G. et al. Sistemas de cultivo e uso de diferentes adubos na produção de silagem e grãos de milho. Acta Scientiarum Agronomy, Maringá, v. 33, n. 1, p. 139-146, 2011.

CARGNELUTTI FILHO, A. et al. Métodos de estimativa do tamanho ótimo de parcelas experimentais de híbridos de milho simples, triplo e duplo. Ciência Rural, Santa Maria, v. 41, n. 9, p. 1509-1516, 2011.

CERETTA, C. A. et al. Nutrient transfer by runoff under no tillage in a soil treated with successive applications of pig slurry. Agriculture, Ecosystems and Environment, Amsterdam, v. 139, n. 4, p. 689-699, 2010.

COMISSÃO DE QUÍMICA E FERTILIDADE DO SOLO - RS/SC (CQFS-RS/SC). Manual de adubação e calagem para os Estados do Rio Grande do Sul e de Santa Catarina. 10. ed. Porto Alegre: CQFS-RS/SC, 2004.

GUARESCHI, R. F. et al. Adubação com cama de frango e esterco bovino na produtividade de feijão azuki (Vigna angularis). Revista Agrarian, Dourados, v. 6, n. 19, p. 2935, 2013.

GUEDES, M. C. et al. Propriedades químicas do solo e nutrição do eucalipto em função da aplicação de lodo de esgoto. Revista Brasileira de Ciência do Solo, Viçosa, v. 30, n. 2, p. 267-280, 2006.

HARGREAVES, J. C.; ADL, M. S.; WARMAN, P. R. A review of the use of composted municipal solid waste in agriculture. Agriculture Ecosystems and Environment, Amsterdam, v. 123, n. 1-3, p. 1-14, 2008. 
KRAY, C. H. et al. Avaliação da aplicação de composto de lixo urbano e lodo de esgoto em dois solos diferentes. Pesquisa Agropecuária Gaúcha, Porto Alegre, v. 17, n. 2, p. 119-125, 2011.

KROB, A. D. et al. Propriedades químicas de um Argissolo tratado sucessivamente com composto de lixo urbano. Ciência Rural, Santa Maria, v. 41, n. 3, p. 433-439, 2011.

LOBO, T. F.; GRASSI FILHO, H. Níveis de lodo de esgoto na produtividade do girassol. Revista de la Ciencia del Suelo y Nutrición Vegetal, Temuco, v. 7, n. 3, p. 16-25, 2007.

LORENTZ, L. H. et al. Plot size and experimental precision for sunflower production. Scientia Agricola, Piracicaba, v. 67, n. 4, p. 408-413, 2010.

MANTOVANI, J. R. et al. Alterações nos atributos de fertilidade em solo adubado com composto de lixo urbano. Revista Brasileira de Ciência do Solo, Viçosa, v. 29, n. 5, p. 817-824, 2005.

MELO, A. V. et al. Extração de nutrientes e produção de biomassa de aveia-preta cultivada em solo submetido a dezoito anos de adubação orgânica e mineral. Semina: Ciências Agrárias, Londrina, v. 32, n. 2, p. 411-420, 2011.

MORAES, M. T.; SILVA, V. R.; ARNUTI, F. Resíduos líquidos de efluentes de agroindústria de carnes na produtividade de girassol. Enciclopédia Biosfera, Goiânia, v. 8, n. 14, p. 843-853, 2012.

NOGUEIRA, F. G. E. et al. Recycling of solid waste rich in organic nitrogen from leather industry: mineral nutrition of rice plants. Journal of Hazardous Materials, Amsterdam, v. 186, n. 2-3, p. 1064-1069, 2011.

PAVINATO, P. S.; ROSELEM, C. A. Disponibilidade de nutrientes no solo: decomposição e liberação de compostos orgânicos de resíduos vegetais. Revista Brasileira de Ciência do Solo, Viçosa, v. 32, n. 3, p. 911-920, 2008.

PIVETTA, L. G. et al. Avaliação de híbridos de girassol e relação entre parâmetros produtivos e qualitativos. Revista Ciência Agronômica, Fortaleza, v. 43, n. 3, p. 561-568, 2012.

RIBEIRINHO, V. S. et al. Fertilidade do solo, estado nutricional e produtividade de girassol, em função da aplicação de lodo de esgoto. Pesquisa Agropecuária Tropical, Goiânia, v. 42, n. 2, p. 166-173, 2012.

RUPPENTHAL, V.; CASTRO, A. M. C. Efeito de composto de lixo urbano na nutrição e produção de gladíolo. Revista Brasileira de Ciência do Solo, Viçosa, v. 29, n. 1, p. 145-150, 2005.

SAMPAIO, T. F. et al. Lodo de esgoto na recuperação de áreas degradadas: efeito nas características físicas do solo. Revista Brasileira de Ciência do Solo, Viçosa, v. 36, n. 5, p. 1637-1645, 2012.
SANTOS, C. C.; BELLINGIERI, P. A.; FREITAS, J. C. Efeito da aplicação de compostos orgânicos de cama de frango nas propriedades químicas de um Latossolo Vermelho escuro cultivado com sogro granífero [Sorghum bicolor (L.) Moench]. Cientifica, Jaboticabal, v. 32, n. 2, p. 134-140, 2004.

SANTOS, H. G. et al. Sistema brasileiro de classificação de solos. 3. ed. rev. ampl. Brasília, DF: Embrapa, 2013.

SARTOR, L. R. et al. Effect of swine residue rates on corn, common bean, soybean and wheat yield. Revista brasileira de Ciência do Solo, Viçosa, v. 36, n. 2, p. 661-669, 2012.

SILVA, A. A. et al. Recycling of nutrients with application of organic waste in degraded pasture. Engenharia Agrícola, Jaboticabal, v. 32, n. 2, p. 405-414, 2012.

SILVA, A. R. A. et al. Desempenho de cultivares de girassol sob diferentes lâminas de irrigação no Vale do Curu, CE. Revista Ciência Agronômica, Fortaleza, v. 42, n. 1, p. 57-64, 2011.

SILVA, H. P. et al. Qualidade física de sementes de girassol produzido sob doses de lodo de esgoto. Revista Verde de Agroecologia e Desenvolvimento Sustentável, Pombal, v. 5, n. 1, p. 1-6, 2010.

SILVA, L. S.; BOHNEN, H. Relações entre nutrientes na fase sólida e solução de um Latossolo durante o primeiro ano da instalação dos sistemas plantio direto e convencional. Ciência Rural, Santa Maria, v. 36, n. 4, p. 1164-1171, 2006.

SOIL SURVEY STAFF (SSS). Keys to soil taxonomy. 11. ed. Washington, DC: USDA/NRCS, 2010.

SPOSITO, G. The chemistry of soils. New York: Oxford University Press, 1989.

TEDESCO, M. J. et al. Análise de solo, plantas e outros materiais. Porto Alegre: UFRGS, 1995.

TRANNIN, I. C. B.; SIQUEIRA, J. O.; MOREIRA, F. M. S. Avaliação agronômica de um biossólido industrial para a cultura do milho. Pesquisa Agropecuária Brasileira, Brasília, DF, v. 40, n. 3, p. 261-269, 2005.

WASTOWSKI, A. D. et al. Caracterização dos níveis de elementos químicos em solo submetido a diferentes sistemas de uso e manejo, utilizando Espectrometria de Fluorescência de Raios-X por Energia Dispersiva (EDXRF). Química Nova, São Paulo, v. 33, n. 7, p. 14491452, 2010. 